\title{
Study on the Treatment Strategy of Batches of the Wounded and Partial First-Aid Procedures in Public Emergencies in Tertiary General Hospitals
}

\author{
Chenyu Wang1, Xiantao Huang1, Xueping Zhao1, Limin Pan1, Yumei Jia1, Tian Tian1, Lijun Gao² \\ ${ }^{1}$ The First Affiliated Hospital of Hebei North University, Zhangjiakou, China \\ ${ }^{2}$ Medical Administration Division Director of Health Committee of Hebei Province, Shijiazhuang, China \\ Email: 529962482@qq.com, *ywc8043522@126.com
}

How to cite this paper: Wang, C.Y., Huang, X.T., Zhao, X.P., Pan, L.M., Jia, Y.M., Tian, T. and Gao, L.J. (2021) Study on the Treatment Strategy of Batches of the Wounded and Partial First-Aid Procedures in Public Emergencies in Tertiary General Hospitals. Open Journal of Emergency Medicine, 9, 25-31.

https://doi.org/10.4236/ojem.2021.92004

Received: April 28, 2021

Accepted: May 24, 2021

Published: May 27, 2021

Copyright $\odot 2021$ by author(s) and Scientific Research Publishing Inc. This work is licensed under the Creative Commons Attribution International License (CC BY 4.0).

http://creativecommons.org/licenses/by/4.0/

\begin{abstract}
Objective: The purpose is to formulate treatment strategies of batches of the wounded and partial first-aid procedures, and further improve the emergency rescue capability of hospitals. Methods: This study analyzed the emergency treatment case that we participated in. In this case, we used various means to start the emergency plan, run the emergency procedures, optimize diagnosis, treatment, and rescue procedures, mobilize medical rescue resources, provide a reference for emergency command decisions, formulate a set of coping strategies of tertiary general hospitals on public emergencies. Results: Through the scientific and effective management of our hospital, 20 wounded have been discharged from the hospital and achieved the ideal effect of zero deaths in the hospital. Conclusions: The new mode of first-aid and health emergency management on the scene of modern disaster needs to find ways to minimize the loss of life and property brought by public emergencies, integrate the various sections of modern disaster medicine, integrate a large number of international and domestic basic and clinical research achievements of disaster first-aid, and upgrade to information, digital system.
\end{abstract}

\section{Keywords}

Public Emergency, Batches of the Wounded, Treatment Strategy, First-Aid Procedure

\section{Introduction}

A public emergency refers to an emergency that occurs suddenly and causes or is 
likely to cause serious social harm, resulting in casualties, property losses, destruction of the ecological environment, and other emergencies that endanger public security and have great social impact. According to Chinese law, public emergency is divided into four kinds: natural disasters, accidents and disasters, public health events, and social security events [1]. Medical institutions are an important part of health emergency system. In response to public emergencies, it undertakes multiple responsibilities such as early warning, on-site rescue, medical treatment, epidemic control, and reducing the social impact caused by public emergencies [2]. In view of the characteristics of public emergencies, taking our hospital responded to the emergency treatment work for "11.28" major deflagration accident in Sinochem Hebei Shenghua Co. Ltd for example, the strategies and some emergency procedures for large public hospitals to deal with public emergencies and batches of the wounded and partial first-aid procedures were discussed.

The situation of the wounded: among the 20 hospitalized wounded, 11 were extremely critical and their lives were in danger at any time; There were 6 critically ill and 3 seriously injured. There were 16 males and 4 females; The average age was 32.9 years (range, 5 - 45 years).

\section{Efficient Command System}

Efficient command system was the premise of health emergency rescue under any conditions. The basic principles of " $\mathrm{O}+4 \mathrm{C}$ " should be followed in the medical rescue in response to any major disasters and emergencies: namely organization, command, control, communication and coordination between different agencies [3]. The systematic organization and management provided an important guarantee for emergency rescue and efficient implementation, and enhanced the response capacity of rescue [4]. Upon receiving the call, the hospital immediately launched the emergency plan, and the on-site administrative and medical personnel formed a temporary on-site treatment team. At the same time, the hospital set up an accident treatment group, including the leading group, the medical care group, the logistics support group and the information coordination group. When the forecast accident treatment time exceeds one week, the temporary party branch for accident treatment should be set up in time to strengthen the mind, stimulate combat effectiveness; strengthen organization and improve leadership; conduct overall planning, implement the logistical support; guarantee strict discipline and steady execution. Ensure that emergency rescue was effective, orderly and effective, and in public emergencies, the leadership of the Communist Party of China should play an active role.

\section{On-Site Management of Emergency Treatment}

The main characteristics of disaster and accident scene: the temporary nature of the organization, tough working conditions, time is tight to get to the rescue site, complex injuries, a large number of injured people need to be treated at the same 
time [5]. Under the leadership of the native government, established a scientific and perfect emergency medical rescue command system and emergency rescue network [6] [7]. Mobilize all available medical resources in the region to implement emergency medical treatment, disease prevention and health protection. While classifying the batches of wounded, the rescue conception of "Sending the patients to the hospital as soon as possible" should be adopted to send the patients to the hospital to get better treatment. The on-site treatment should follow the principles: saving the life before treating the injury, give priority to seriously injured patients, the main task of medical staff was to treat and cure, the main task of other personnel was to carry patients to a safe area, transferred companied by treating, and left the scene of the accident as soon as possible [8].

\section{Establishing Health Emergency Medical Rescue Network System}

The pre-hospital first aid, specialized treatment, psychological treatment, rehabilitation treatment and other whole-chain processes management were fully implemented. Experts from trauma, burn, surgery, internal medicine, ICU, anesthesia, imaging, infection, psychology and nursing, etc., were transferred to establish a model of "one person and one team" for severe patients and unified management of mild patients. Special teams, such as catheters, hospital infection, ECMO and training, were set up to take charge of special medical treatment and nursing treatment for all the wounded. Established an expert consultation system and invited well-known experts for consultation timely. According to the actual situation of the medical care group and the hospital to establish various contingency plan for patient rescue [9]. Held a daily meeting on the patient's condition, the medical care group and the special group report, analyzed and discussed the patient's condition to determine the next diagnosis and treatment plan. A medical treatment system combining points, lines and planes should be formed [10].

\section{Create a Safe and Effective Green Rescue Pathway}

A new mode of information-based, networked, integrated, interlocking and seamless on-site treatment suggests: It is the central step to reduce the mortality rate and disability rate of disaster injury and complex injury patients to establish emergency and quick first-aid green pathway [6] [11] [12] [13]. Pay attention to the platinum $10 \mathrm{~min}$ and gold $1 \mathrm{~h}$ rescue time after injury, so that the injured could obtain the most accurate treatment timely [14] [15] [16]. According to the situation on the scene, a joint rescue team (including polices, fire fighters, chemical experts and volunteers) was set up to enter the accident site together [17]. At the same time, the medical rescue network, communication network and traffic network green rescue pathways should been opened. Deploy the follow-up rescue forces, determine the medical institutions for the injured, arrange the transport of critical patients, collect on-site information, report the on-site 
medical and health rescue situation in time, explain the patients' condition to the backup medical staff, and shorten the time from the injury to the operation as far as possible.

\section{Strengthen the Training of Medical Rescue Teams for Health Emergencies}

Due to the large number of casualties and complex types of injuries in public emergencies, the cooperation of multi-disciplinary and multi-professional medical staff was needed. In addition, the transferred medical and nursing staff were from multiple professions, and the training group carried out multiple, multisubject, targeted medical, nursing, nosocomial infection knowledge training. The medical staff were formed a "Standard model", they could practice, learn and apply simultaneously. Through multi-disciplinary discussion, combined with consultation opinions, evaluated the patient's condition comprehensively, effectively and rationally allocated and utilized the limited medical resources [18].

\section{High Efficiency and Mobility of Technical Medical Equipment, and Medicinal Material Equipment}

After the simultaneously established logistic support group and the medical care group, checked the patients' situation with the information coordination team immediately, including patient number, age, main diagnosis and treatment plan of critically ill, severe and mild patients, etc. Participate in patients' condition discussions, formulated procurement management plans for emergency materials (equipment, consumables, drugs, etc.), prohibited illegal procurement process and substandard products. According to the current emergency supplies reserve situation of the hospital, actively purchased the required materials to ensure the completion of the rescue mission to the maximum extent.

\section{Enlightenment}

Through the scientific and effective management of our hospital, a large number of the wounded have been discharged from hospital and achieved the ideal effect of zero deaths in the hospital. Summarizing the experience of this treatment, it is considered that tertiary general hospitals should pay attention to the following points when dealing with public emergencies and batches of wounded:

\section{1) Innovate treatment strategies and methods}

Infection, a common post-traumatic complication, has been identified as the third highest cause of death among batches of wounded [19]. According to the patient's condition and the actual situation of our hospital, this study has created many treatment strategies and methods that are not available in China, like establishing a catheter group, hand over to the next shift daily, attending daily patient condition discussion and establishing ECMO group consisted of emergency physician. The catheter group is in charge of catheter management for all 
wounded patients, including catheter placement, catheter replacement, catheter care and other catheter-related treatment. Avoid infection caused by the catheter. ECMO group ensures emergency rescue of patients at any time. In this rescue, ECMO group was started 7 times and the patients were all rescued successfully. The catheter group and ECMO group played a very important role in the rescue process.

\section{2) Effective personnel and material scheduling guarantee}

Medical care groups were formed by transferring medical staff from the whole province, and a "one-man-one-team" medical treatment model has been formed. Procure the medical instruments, equipment and drugs needed in the treatment process as soon as possible. It was of great significance to establish emergency material warehouse and emergency material dispatching system in hospital. Calculated the daily consumption of the medical group and the hospital, controlled the material distribution, procured from different approaches to meet the needs of the rescue and prevented illegal procurement and other illegal phenomena in special period [20].

\section{3) Training of first-aid knowledge in emergency condition}

In the face of the characters of public emergency, including large number of the injured patients, complex and rapidly changed condition of the patients, and the major and specialty difference of the transferred medical staff from different places, training could evidently improve the capability of treatment in emergency condition. Before the transferred staff started to work, training of basic knowledge and skills should have been conducted. After begin of the work, professional skills improvement training should be conducted. Key steps: sort out the medical knowledge required for the emergency mission, intra-group teach and learn from each other, highlight the priority of rescue and strengthen targeted training [21]. We thought the key points were the "three implementation": training plan implementation, training quality implementation and training effect implementation. Through creating targeted circulated-training, supervision of the whole process, mutual supervision, the quality of training could be effectively guaranteed. And payed attention to the real-time update of the theoretical knowledge of the medical care group.

\section{4) Treatment information statistics and feedback}

After this rescue, we found timely and accurate information statistics was very important for the treatment of the wounded, resource allocation, requirement of the media and social stability. However, it was easy to be ignored in the early stage of emergency treatment, which leaded to the delay of information statistics and poor accuracy of follow-up information. Therefore, the process of information statistics in emergency condition should be clearly stipulated in the contingency plan of the hospital. In this rescue, an information coordination group has been established, and the working responsibilities and principles have been defined to ensure that the rescue work was timely, accurate and error-free in the emergency statistical information work [22]. 


\section{Conclusion}

The new mode of first-aid and health emergency management on the scene of modern disaster needs to find ways to minimize the loss of life and property brought by public emergencies, integrate the various sections of modern disaster medicine, integrate a large number of international and domestic basic and clinical research achievements of disaster first-aid, and upgrade to information, digital system. The connection between pre-hospital first-aid, hospital first aid and rescue of critical patients is the key to improve the first-aid efficiency and exert the function of hospital treatment. At present, there is still a gap between us and the latest development trend of modern disaster on-site first-aid and health emergency management, which includes "socialization of first-aid, networked structure, on-site rescue and popularization of knowledge". We need to build on these patterns to create new and better models [23].

\section{Funding}

Social science development research project of Hebei province, Number: 20200303130.

\section{Conflicts of Interest}

The authors declare no conflicts of interest regarding the publication of this paper.

\section{References}

[1] (2007) Emergency Response Law of the People's Republic of China.

[2] Yu, X., Tang, X. and Yang, Y. (2012) Current Situation of Public Health Emergency Response Capacity of Medical Institutions above Second Level in Hongkou District. Chinese Journal of Public Health Management, 28, 585-587.

[3] Yue, M. and Wang, L. (2018) Expert Consensus on Health Emergency Rescue and Disposal of Disaster Accidents. China Medical Electronic Audio Visual Press, Beijing, 1-188.

[4] Zhou, S., Jin, Y. and Zhen, Z. (2020) Research Progress and Enlightenment of Operation Mechanism Optimization of Emergency Medical System. China Hospital management, 40, 52-54.

[5] Yue, M., Wang, L., Li, Q., et al. (2017) Expert Consensus on First Aid and Health Emergency Response in Disaster Scene (2017). Chinese Journal of Health Emergency, 3, 1-11.

[6] Yue, M., He, D. and Qin, G. (2009) The Experience of Establishing a New Mode of Information, Network, Integration and Seamless On-Site Treatment. China General Practice, 12, 131-134.

[7] Cai, L. and Yang, X. (2015) Research on the Application of Big Data in Social Public Opinion Monitoring and Decision Making. Administrative Tribune, No. 2, 1-10.

[8] Wu, X. (2010) Early Warning of Public Emergencies. China Hospital Management, 30, 9-10.

[9] Chen, Z., Zhang, Y. and Zhou, H. (2015) Current Situation and Countermeasures of Public Health Emergency Management in Guizhou Province. Chinese Journal of 
Health Emergency, 1, 35-36.

[10] Qin, X. and Qin, S. (2016) Research and Application of Health Emergency Assessment at Home and Abroad. Disaster Medicine and Rescue, 1, 135-136.

[11] Yue, M. and Zhou, P. (2014) Strategies, Principles and Application of Key New Technologies and Methods for On-Site Treatment of Disaster Injured and Mass Injured. Chinese Journal of Damage and Repair, 9, 7-10.

[12] Yang, X. and Lin, Z. (2013) Guiding Opinions on Strengthening the Construction of Emergency Green Channel in Secondary and Tertiary Hospitals. Emergency Medicine in China, 23, 333-334.

[13] Mellon, D. (2015) Evaluating Evidence Aid as a Comlex, Multicomponent Knowledge Translation Intervention. Journal of Evidence-Based Medicine, 8, 25-30. https://doi.org/10.1111/jebm.12135

[14] Gu, X. and Li, Z. (2016) Meta Analysis of Platinum 10 Minute Heart Rate in Chinese Patients with Prehospital Cardiac Arrest. Chinese PLA Medical Journal, 3, 1-14.

[15] He, Z. (2017) Discussion on the Golden Time of Cardiopulmonary Resuscitation. Chinese Journal of Health Emergency, 3, 75-78.

[16] Hu, S. and He, Z. (2017) Study on the Public's Willingness to Implement "Platinum Ten Minutes" First Aid and Its Influencing Factors. Chinese Journal of Emergency Medicine, 26, 976-978.

[17] Hazinski, M.F., Nolan, J.P., Aickin, R., Bhanji, F., Billi, J.E., Callaway, C.W., et al. (2015) Part1: Executive Summary: 2015 Internationgal Consensus on Cardiopulmonary Resuscitation and Emergency Cardiovascular Care Science with Treatment Recommendations. Circulation, 132, S2-S39.

https://doi.org/10.1161/CIR.0000000000000270

[18] Burlet-Vienney, D., Chinniah, Y. and Bahloul, A. (2014) The Need for a Comprehensive Approach to Managing Confined Space Entry: Summary of the Literature and Recommendations for Next Steps. Journal of Occupational and Environmental Hygiene, 11, 485-498. https://doi.org/10.1080/15459624.2013.877589

[19] Liang, H. and Yue, M. (2017) Expert Consensus on Infection Prevention Strategy for Batch of Wounded Persons (2017). Chinese Journal of Health Emergency, 3, 65-71.

[20] Li, X., Wang, Y. and Wang, F. (2020) Research on the Improvement of Emergency Logistics Based on Blockchain Application in the Case of Public Health Emergencies. Contemporary Economic Management, 42, 57-63.

[21] Ong, M., Perkins, G.D. and Cariou, A. (2018) Out-of-Hospital Cardiac Arrest: Prehospital Management. Lancet, 391, 980-988.

https://doi.org/10.1016/S0140-6736(18)30316-7

[22] Chen, R.J., Strait, K.M., Dharmarajan, K., Li, S.-X., Ranasinghe, I., Martin, J., et al. (2015) Hospital Variation in Admission to Intensive Care Units for Patients with Acute Myocardial Infarction. American Heart Journal, 170, 1161-1169. https://doi.org/10.1016/j.ahj.2015.09.003

[23] Norum, J., Hovland, A., Balteskard, L., Trovik, T., Haug, B., Hansen, F.H., et al. (2017) Treatment of Acute Myocardial Infarction in the Sub-Arctic Region of Norway. Do We Offer an Equal Quality of Care? International Journal of Circumpolar Health, 76, Article ID: 1391651. https://doi.org/10.1080/22423982.2017.1391651. 